ECOLOGICA, Vol. 28, No 104 (2021), 503-509

https://doi.org/10.18485/ecologica.2021.28.104.3

Originalni naučni rad

UDC: $502.174 .3: 631.11$

\title{
Upotreba obnovljivih izvora energije na poljoprivrednim gazdinstvima
}

\section{Use of renewable energy sources on agricultural holdings}

\author{
Aleksandra Gajdobranski * ${ }^{1 *}$ Vera Krmpot ${ }^{2}$, Maja Anđelković3 \\ 1,2Fakultet za poslovne studije i pravo, Univerzitet Union - Nikola Tesla, Beograd, Srbija / \\ Faculty of Business Studies and Law, University Union - Nikola Tesla, Belgrade, Serbia \\ ${ }^{3}$ Fakultet za informacione tehnologije i inženjerstvo, Univerzitet Union - Nikola Tesla, Beograd, Srbija / \\ Faculty of Information Technology and Engineering, University Union - Nikola Tesla, Belgrade, Serbia \\ ${ }^{*}$ Autor za prepisku / Corresponding author
}

Rad primljen / Received: 01.09.2021, Rad prihvaćen / Accepted: 05.11.2021.

\begin{abstract}
Sažetak: Upotreba obnovljivih izvora energije, ima ključnu ulogu u unapređenju poljoprivredne proizvodnje. Ova proizvodnja najviše je zastupljena u okviru porodičnih gazdinstava, gde dominantnu ulogu imaju mala i srednja poljoprivredna gazdinstva. U tom pogledu, strateški cilj svake države je očuvanje biološke raznolikosti, čime se stvaraju povoljni uslovi za poboljšanje i unapređenje biodiverziteta. Samim tim, svest poljoprivrednih proizvođača počinje da se menja kroz tzv. implementaciju održivih sistema poljoprivredne proizvodnje, među kojima značajno mesto zauzima biomasa i biogas. Najstariji obnovljivi izvor energije koji je čovek koristio predstavlja biomasa, koja je produkt najrazličitijih proizvoda biljnog i životinjskog sveta. U pitanju su biorazgradivi delovi proizvoda, otpada ili ostatka iz poljoprivrede, kao i delovi šumskog, industrijskog i gradskog otpada. Unapređenjem tehnologije proizvodnje na poljoprivrednim gazdinstvima, tzv. aneorobnom digestijom biomase, dobija se biogas. Upotreba biomase i biogasa treba da ima stimulativni i razvojni karakter u izmenjenim tržišnim uslovima, što doprinosi povećanju intenzivnosti proizvodnje na poljoprivrednim gazdinstvima. Naglasak je na permanentnom transferu znanja i razvoju ljudskih potencijala, što bi doprinelo daljoj modernizaciji obnovljivih tehnologija, koje bi se koristile u proizvodnji obnovljivih izvora energije. Napred navedena tema je u skladu sa društveno ekonomskom situacijom koju je obležio covid-19, gde su i dalje najbrojnija mala i srednja poljoprivredna gazdinstva.
\end{abstract}

Ključne reči: biomasa, biogas, održiva proizvodnja, obnovljive tehnologije.

\begin{abstract}
The use of renewable energy sources has a key role in improving agricultural production. This production is mostly represented within family farms, where the dominant role is played by small and medium agricultural farms. In this regard, the strategic goal of each country is to preserve biodiversity, which creates favorable conditions for the improvement and enhancement of biodiversity. Therefore, the consciousness of agricultural producers is beginning to change through the so-called implementation of sustainable agricultural production systems, among which a significant place is occupied by biomass and biogas. The oldest renewable energy source used by man is biomass, which is a product of various products of flora and fauna. These are biodegradable parts of products, waste or residues from agriculture, as well as parts of forest, industrial and municipal waste. By improving the production technology on agricultural farms, the so-called by anaerobic digestion of biomass, biogas was obtained. The use of biomass and biogas should have a stimulating and developmental character in the changed market conditions, which contributes to increasing the intensity of production on agricultural farms. The emphasis is on the permanent transfer of knowledge and the development of human resources, which would contribute to the further modernization of renewable technologies, which would be used in the production of renewable energy sources. The above topic is in line with the socio-economic situation marked by covid-19, where small and medium-sized farms are still the most numerous.
\end{abstract}

Keywords: biomass, biogas, sustainable production, renewable technologies.

\footnotetext{
1orcid.org/0000-0002-4978-5553, e-mail: aleksandra.gajdobranski@fpsp.edu.rs

2orcid.org/0000-0002-4039-5807, e-mail:vera.krmpot@fpsp.edu.rs

3orcid.org/0000-0002-5507-9831, e-mail:maja.andjelkovic@fpsp.edu.rs
} 


\section{UVOD / INTRODUCTION}

Obnovljivi izvori energije, od kojih su pojedini sasvim novi, a neki se koriste već duže vremena, pored biomase i biogasa obuhvataju i energiju vetra, solarnu energiju, hidroenergiju, energiju plime i oseke, geotermalnu energiju. Neki od ovih izvora omogućavaju profitabilnu proizvodnju električne ili termo energije, dok su pojedini još uvek u razvojnoj fazi, pa se njihova komercijalna primena tek očekuje (Mentus, Jovanović, 2020).

Poljoprivredna gazdinstva kao obnovljive izvore energije koriste biomasu i biogas, koji obuhvataju najrazličitije proizvode iz biljnog i životinjskog sveta. Iz obnovljivih izvora - biomase, proizvedena su biogoriva koja su obliku tečnih ili gasovitih goriva, a koriste se za potrebe prevoza. Ona mogu biti proizvedena neposredno iz biljaka ili posredno iz industrijskog, komercijalnog, domaćeg i poljoprivrednog otpada (Todorović i dr., 2015).

Evropska unija je postavila cilj kojim udeo obnovljivih izvora energije u ukupnoj energetskoj potrošnji u 2020. godini, mora biti $20 \%$, čime je dala snažan podsticaj za jaču primenu biomase, obnovljivog izvora sa znatnim potencijalom. Razlog tome je i u činjenici da upotreba biomase doprinosi smanjenju emisije staklenih gasova, zavisnosti od uvoza nafte i fosilnih goriva, povećanju sigurnosti snabdevanja energijom, razvoju tehnologije i industrije za upotrebu biomase koja doprinosi rastu broja novih radnih mesta, razvoju konkurentnosti, kao i regionalnom i ruralnom razvoju (http://powerlab.fsb.hr/). Iz biomase dobija se biogas kao izvor energije iz obnovljivih izvora, a u pitanju su delovi ostataka u poljoprivrednoj proizvodnji poput tečnog i čvrstog stajnjaka, energetskog bilja, ostataka biomase nastalih preradom poljoprivrednih proizvoda i to onih koji ne sadrže opasne materije, kao i ostalih biomasa (Cvetković et al., 2014).

Ako se osvrnemo na Republiku Srbiju, kada su u pitanju obnovljivi izvori energije, najveći udeo zauzima biomasa (oko 49\%). Njen potencijal potiče najvećim delom iz poljoprivrednog otpada i drvne biomase. Tim povodom, potrebna je izgradnja potencijala električne i toplotne energije iz obnovljivih izvora, koji bi se koristili na poljoprivrednom gazdinstvu. Ovo uključuje investicije u opremanje postrojenja za proizvodnju energije iz obnovljivih izvora za sopstvenu potrošnju, posebno u solarnu energiju, postrojenja za biomasu, kao i kotlove za sagorevanje biomase. Dokazano je da preko $40 \%$ električne energije se proizvodi iz sagorevanja uglja, dok preko $40 \%$ svetske populacije koristi biomasu kao energent $u$ procesu pripremanja svakodnevnih obroka. Kao direktni energetski izvori koji distribuiraju raspoloživu energiju ka poljoprivrednom sistemu, obnovljivi izvori energije u odnosu na potrebe poljoprivrede predstavljaju odličnu kombinaciju. Ovo je iz razloga, što se snaga vetra, sunca i biomasa mogu koristiti neograničeno, gde kroz proizvodne uštede u utrošku fosilnih goriva poljoprivredna gazdinstva mogu doći i do dugoročnog izvora prihoda.

$\mathrm{U}$ izmenjenim uslovima poslovanja u poljoprivrednom sektoru u periodu pandemije COVID-19, u Respublici Srbiji je omogućeno kretanje za obavljanje svih sezonskih poslova u ratarstvu, povrtarstvu, voćarstvu i na farmama; obavljena je prolećna setva na oko $1,5 \mathrm{mil} / \mathrm{ha}$ površine i zaštita ozimih kultura na oko $700 \mathrm{hilj} / \mathrm{ha}$; sprovedena je dostava zaštitnih hemijskih sredstava za useve, semena, rezervnih delova za mašine na adrese gazdinstava; umesto edukativnih predavanja - skupova proizvođačima je ponuđeno korišćenje internet prezentacija koje su nudile pojedine kompanije.

\section{UPOTREBA BIOMASE NA POLJOPRIVREDNIM GAZDINSTVIMA / \\ USE OF BIOMASS ON AGRICULTURAL HOLDINGS}

Biomasu kao obnovljiv izvor energije sačinjavaju biorazgradivi delovi proizvoda, otpada ili ostataka iz poljoprivrede, šumski otpad i otpad srodnih industrija kao i biorazgradivi delovi industrijskog i gradskog otpada. Kada je reč o poljoprivrednom sektoru, biomasu čine sekundarni ili tercijalni proizvodi iz poljoprivrede (slama pšenice, soje, ječma, raži, kukuruzovina, stabljike suncokreta i dr.). Utvrđeno je da udeo obnovljivih izvora energije u ukupnoj energetskoj potrošnji u 2020. godini mora biti $20 \%$, a što je bio krajnji cilj Evropske unije, čime je dat snažan podsticaj za jaču primenu biomase kao obnovljivog izvora sa znatnim potencijalom. Potencijal korišćenja poljoprivredne biomase kao izvora energije, određuje dugoročnu održivost, koja uzima u obzir i efekte konkurentnosti kada je u pitanju proizvodnja hrane, zatim uticaj na biodiverzitet, kao i emisiju ugljendioksida prilikom sagorevanja. Stoga se upotreba biomase mora posmatrati u celom životnom ciklusu, počev od proizvodnje biomase, preko logistika, pa sve do konačne upotrebe (Gajdobranski i dr., 2020).

Prirodni i tehnički potencijal korišćenja obnovljivih izvora energije je dovoljan, kako bi zadovoljio ukupne energetske zahteve celokupne svetske populacije. Razlog je u tome, što je njihov prirodni dnevni potencijal čak 20 hiljada puta veći od dnevne potrošnje nuklearnih i fosilnih goriva. Na slici 1., vidimo da najveći prirodni potencijal od ukupnih obnovljivih izvora energije zauzima biomasa $66,1 \%$, zatim sledi snaga vode $21,2 \%$, snaga vetra $6,9 \%$, geotermalna energija $4,7 \%$ i na kraju solarna energija $1,1 \%$. 


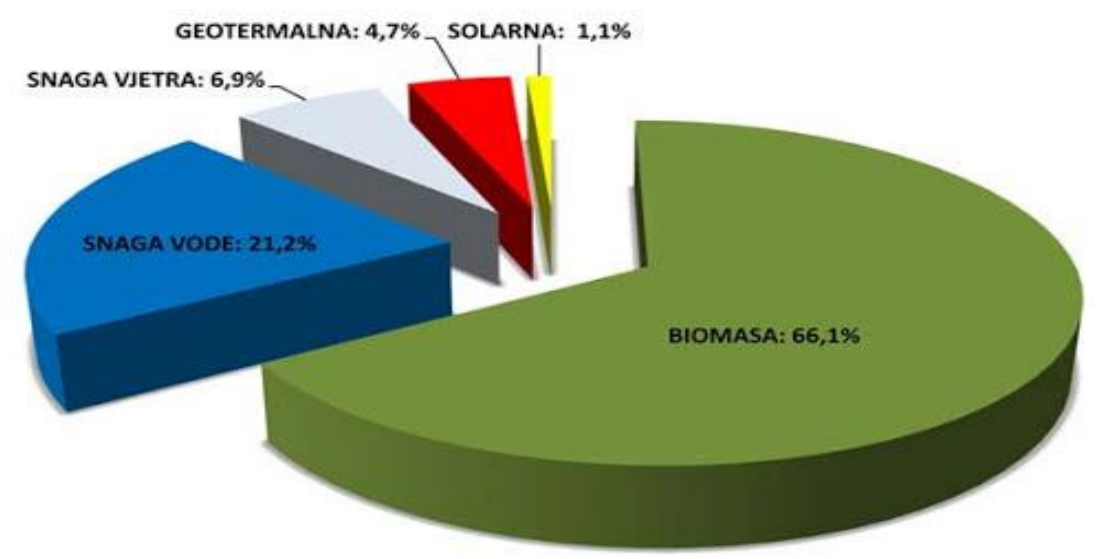

Slika 1. Obnovljivi izvori energije (izraženo u procentima)

Figure 1. Renewable energy sources (expressed as a percentage) Izvor / Source: http://natalijadikovic. weebly.com/

Prema novijoj direktivi Evropske Komisije posle 2017. godine, na tržištu ne mogu da se nađu biogoriva čiji je uticaj na smanjenje emisije gasova ispod $60 \%$. Biodizel iz uljane repice koji se u Srbiji proizvodi spada u tu kategoriju, što znači da posle 2017. godine biodizel koji je proizveden na taj način, nije uziman u obzir. Zbog toga, nije ni bilo većih podsticaja proizvodnje na poljoprivrednim gazdinstvima u Srbiji dok se i situacija u Evropskoj uniji u potpunosti ne razjasni. $U$ odnosu na druge nosioce energije, potrošnja tečnih goriva iz biomase (biodizela) predstavlja jedan od najvažnijih ekoloških energenata, a očekuje se da tako ostane i posle 2030. godine (Gajdobranski, 2020). Dosadašnje studije i analize pokazale su da je biomasa najznačajniji potencijal obnovljivih izvora energije u Srbiji, od čega je $48 \%$ poljoprivredna a $44 \%$ drvna biomasa. Drvna biomasa je najzastupljenija u planinskim predelima centralne Srbije i njen stepen trenutnog korišćenja je vrlo visok (iznosi preko $70 \%$ ), dok je poljoprivredna biomasa najzastupljenija na severu Srbije. Međutim, i pored velike rasprostranjenosti njen potentecijal se koristi u zanemarljivom procentu (manje od 2\%) (http://www.zelena energija). Dokazano je da posle obavljanja poljoprivrednih radova na $3,47 \mathrm{mil} / \mathrm{ha}$ u Srbiji ostane neiskorišćeno više od 12,5 mil/t biomase. Od toga u AP Vojvodini na $1,7 \mathrm{mil} / \mathrm{ha}$ čak $9 \mathrm{mil} / \mathrm{t}$ ili $72 \%$ (Prvi poslovni list poljoprivrednika i savetodavaca u Srbiji, 2020).

$\mathrm{Na}$ osnovu kriterijuma održivosti, Direktive o promovisanju upotrebe energije iz obnovljivih izvora, a koje se odnose na poljoprivredne sirovine uzgojene u Evropskoj uniji i koje se upotrebljavaju za proizvodnju biogoriva, moraju biti u skladu s minimalnim zahtevima za dobro poljoprivredno i ekološko stanje i određenim propisanim zahtevima $u$ vezi $s$ upravljanjem koji su utvrđeni u okviru Zajedničke poljoprivredne politike (ZPP-a). Tako na primer, za proizvodnju sirovina za biogoriva koja se upotrebljavaju u
Evropskoj uniji u 2012. godini bilo je potrebno ukupno $7,8 \mathrm{mil} / \mathrm{ha}$ zemljišta, od čega je $4,4 \mathrm{mil} / \mathrm{ha}$ zemljišta bilo u Evropskoj uniji (3\% ukupnog kultiviranog zemljišta), dok je 3,5 mil/ha izvan Evropske unije. U poljoprivredi, voda predstavlja energetski intenzivnu aktivnost, gde najveći deo vode iskoriste poljoprivredna gazdinstva (Subić et al., 2017). Primera radi, samo za potpuno navodnjavanje različitih useva potreban je transfer 2-10 megalitra vode po hektaru u uslovima poljoprivrede Australije, pri čemu na ove potrebe odlazi preko $50 \%$ ukupno potrošene energije na gazdinstvu. S druge strane, najveći potrošač voda kao i glavni izvor prihoda i zaposlenosti poljoprivrednih gazdinstava jeste navodnjavanje u poljoprivredi u Mediteranskom regionu. Veliki problem predstavlja održivost poljoprivredne proizvodnje zbog sve većih nedostataka vode, usled čestih i sve većih suša. Javnost je takođe izrazila zabrinutost da će se kulture i zemljišta namenjena proizvodnji hrane početi upotrebljavati za proizvodnju biogoriva, i to zbog upotrebe kultura kao što su kukuruz, pšenica, šećerna repa ili šećerna trska za proizvodnju biogoriva (https://www.eca.europa.eu/).

Stručna javnost smatra da ne bi trebalo celokupnu biomasu dobijenu iz poljoprivrede koristiti za proizvodnju energije. Jedna od alternativa korišćenja biomase jeste pellet. On predstavlja moderan oblik zgusnute biomase i široko se koristi u Evropskoj uniji kao izvor energije. Poljoprivredni proizvođači se najčešće rukovode idejom da najveći deo biomase treba zaorati kako bi se zemljište oporavilo od iznošenja mineralnih materija i na taj način pripremilo za novu sezonu i setveni period. U stočarstvu, s druge strane, biomasa se najčešće koristi kao prostirka za životinje. U praksi, većina poljoprivrednih proizvođača žetvene ostatke najčešće spaljuje na svojim parcelama pri čemu dolazi do zagađenja životne sredine. Ovakvim postupkom proizvođači neracionalno koriste biomasu 
što istovremeno dovodi i do kršenja zakona koji zabranjuje paljenje biomase na poljoprivrednim parcelama (https://educons.edu. rs). Na razvoj i promovisanje biogoriva danas mnogo više utiče sektor poljoprivrede nego energetski sektor. Većina programa koji promovišu korišćenje biogoriva zavise od vladinih subvencija što može dovesti do poremećaja cena na tržištu i predstavljati veliko opterećenje za državni budžet. Ako bi se cene nafte održale na ovako visokom nivou, i uz postojani razvoj sve efikasnijih i jeftinijih tehnologija, biogoriva bi u bližoj budućnosti mogla postati ekonomski isplativa alternativa $u$ mnogim državama (Gajdobranski, 2020).

\section{UPOTREBA BIOGASA NA POLJOPRIVREDNIM GAZDINSTVIMA / \\ USE OF BIOGAS ON AGRICULTURAL HOLDINGS}

Biogas se može dobiti od tečnog i čvrstog stajnjaka, energetskog bilja (tj. od ostataka iz poljoprivredne proizvodnje); zatim od ostataka biomase nastalih preradom poljoprivrednih proizvoda (ali koji ne sadrže opasne materije); kao i ostalih biomasa. Biogas nastaje anaerobnom digestijom biomase. Danas su predmet velikog interesovanja tzv. biofarme na poljoprivrednim gazdinstvima. To su postrojenja koja anaerobnom kodigestijom stajnjaka i ostalih supepublicistrata proizvode biogas. Tako npr. u Republici Srbiji je Nacionalnim akcionim planom za obnovljive izvore energije predviđeno da se do 2020. godine izgradi 30 biogasnih postrojenja, a do sada je izgrađeno 12, što je ipak dobar pomak (https://www. agromedia).

Kod postrojenja za proizvodnju biogasa, moraju se uzeti u obzir vrste i karakterisitike korišćenih supstrata. Moguće je kombinovati razne opreme za proizvodnju biogasa, čija konfiguracija utiče kako na količinu tako i na kvalitet (tj. procenat metana) biogasa. Stoga je poželjno, da se proces odabira opreme poveri stručnim licima koji su odgovorni i za njen kvalitet. Što se tiče supstrata, oni se mogu podeliti na tečne (koji se nakon privremenog skladištenja u rezervorima, podvrgavaju procesu pasterizacije i šalju u digestor) i čvrste supstrate (koji se skladište u silažama ili podzemnim betonskim rezervoarima tzv. biloški otpad iz prehrambene industrije, i oni se nakon prethodne manipulacije i pripreme transportuju u digestor) (Gajdobranski, 2020). U anaerobnom digestoru ili fermentoru se odvijaju svi neophodni biološki i hemijski procesi koji za rezultat u poslednjoj fazi digestije imaju izdvajanje biogasa. Kako bi anaerobne bakterije, koje su zadužene za proizvodnju biogasa, imale što idealnije uslove, neophodno je da se pored adekvatne i redovne ishrane biološkim otpadom, obezbedi kontinuirano mešanje i održavanje konstantne temperature unutar digestora. Prosečno vreme zadržavanja supstrata u digestoru je od 30-60 dana, nakon čega se tečni supstrat transportuje do posebne otvorene lagune za skladištenje fermentisanog supstrata. Pre istakanja u lagunu, supstrat prolazi kroz separator, koji razdvaja čvrstu i tečnu frakciju. Ovako dobijen biogas nije pogodan za direktno korišćenje, već je neophodan tretman kojim se izdvaja sumpor, voda i ostale štetne primese. Nakon tretmana, biogas je spreman za korišćenje u kotlu ili kogenerativnom postrojenju. U slučaju prekomerne produkcije biogasa, biogas se sagoreva na baklji, što predstavlja apsolutno neškodljiv proces kada je u pitanju zagađenje atmosfere. Postrojenje za proizvodnju biogasa na poljoprivrednom gazdinstvu, a koji može biti: deponijski, poljoprivredni, iz drvnih ostataka, iz industrijske proizvodnje, prikazano je na slici 2.

Poljoprivredna gazdinstva koja žele da razviju nov proizvodni sektor, mogu da proizvode biogas (Nemački centar za istraživanje biomase, 2016) radi: proširenja svoje osnovne delatnosti, osiguranja od rizika zbog izostanka prihoda korišćenjem zagarantovanih cena za električnu energiju iz biogasa, obezbeđenja likvidnih sredstava kako bi nadoknadili troškove poslovanja u toku godine, energetskog iskorišćenja glavnih i sporednih proizvoda, smanjenja emisija štetnih gasova i neprijatnih mirisa usled skladištenja, smanjenja emisija štetnih gasova i neprijatnih mirisa zbog razastiranja đubriva po poljoprivrednim površinama, povećanja raspoloživosti hranljivih materija za biljke, nezavisnog snabdevanja energijom, ukupnog poboljšanja imidža i spremnosti za preuzimanje rizika (Subić et al, 2017).

U ratarskoj proizvodnji, gazdinstva svake godine sve manje ostvaruju prodaju u žetvi, a nakon žetve i sve češće rod ostavljaju „na otvoreno" skladištarima ili prerađivačima. Skladišta koja imaju poljoprivrednici na svojim imanjima nemaju savremene kapacitete ni za $30 \%$ svoje ukupne proizvodnje. Prostor za čuvanje klipa kukuruza, a što se događa sve ređe, preuređuju za čuvanje zrna. Na drugoj strani, kupci robe, prerađivači $\mathrm{i}$ industrijska prerada, raspolažu sa više od 1.000 različitih skladišta, u kojima je obezbeđen prostor za oko $11 \mathrm{mil} / \mathrm{t}$ zrna. Ponuda radne snage za rad, pre svega, u voćarstvu i povrtarstvu za vreme pandemije se nije menjala. Praktično, objavljeni dolazak iz inostranstva oko 400.000 naših državljana različitog zanimanja i radnih veština, nije uticao na cenu radnog časa, niti povećanje ponude radne snage. Zavisno od regiona, gazdinstva kojima je potrebna radna snaga, plaćaju različito ove usluge. $U$ južnim krajevima jedan čas rada se plaća 200 dinara i to uz 2 obroka, dok je na severu zemlje ta cena rada od 250 do 300 dinara po času i sa jednim obrokom (Gajdobranski i dr., 2020). Zakon o angažovanju radnika na određeno vreme, se sve manje primenjuje. 


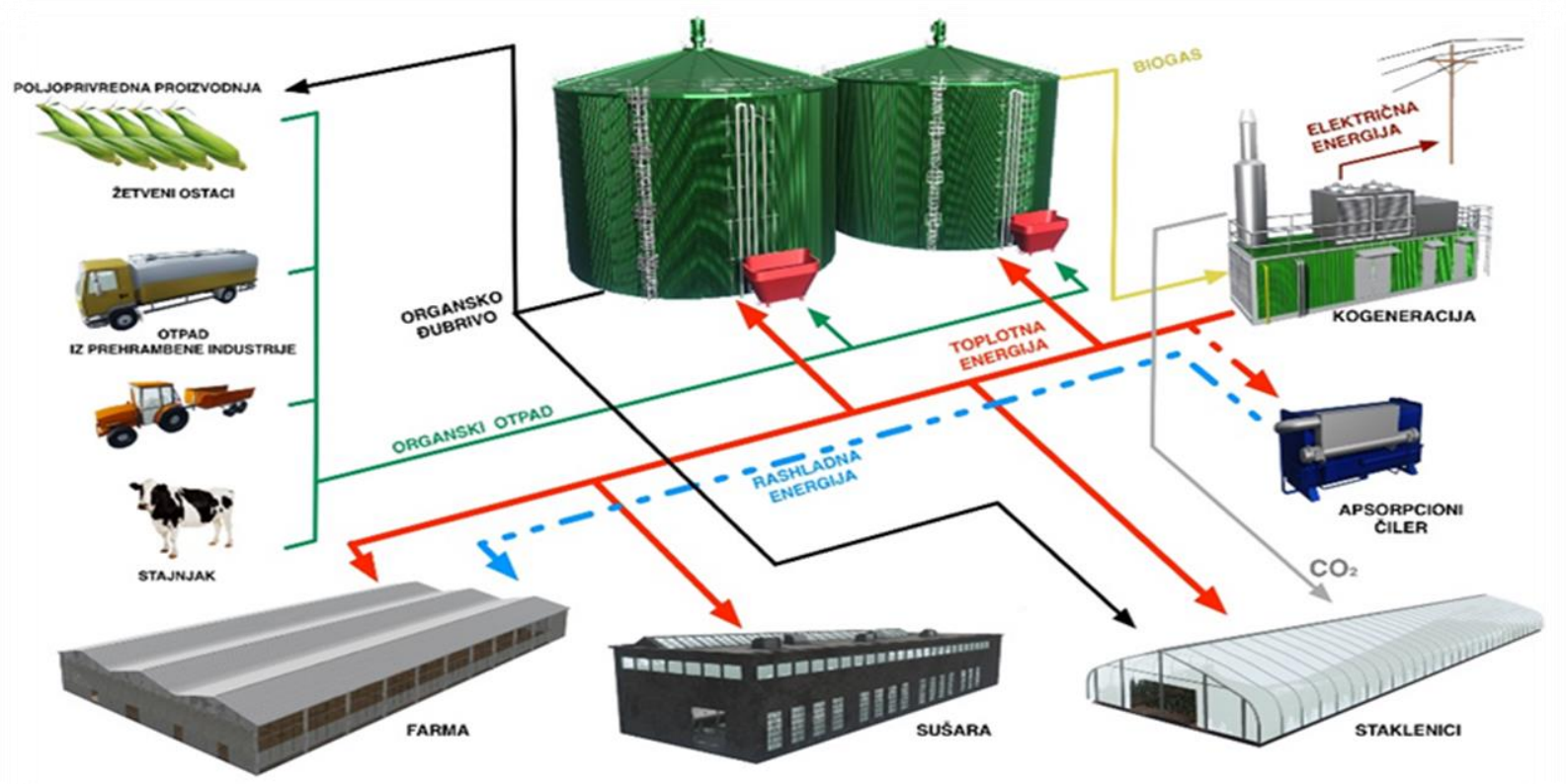

Slika 2. Postrojenje za proizvodnju biogasa na poljoprivrednom gazdinstvu Figure 2. Plant for biogas production on an agricultural farm Izvor / Source: http://www.esco.rs/biogas.html

Poput tržišta mnogih drugih poljoprivrednih proizvoda, globalna finansijska kriza prouzrokovana usled pandemije, ozbiljno je uticala na poljoprivredne proizvođače, kroz nižu likvidnost i manji porast troškova finansiranja. Cene koje se formiraju prema uslovima tržišta, postaju stabilnije tamo gde je razvijenija privreda i masovnija proizvodnja, što uslovljava i veću ponudu proizvoda. A da bi se postigla konkurentnost cena, presudne su bruto cene koje plaća kupac, što se znači da se mora ući u kompletnu strukturu cena i analizirati amortizacija, plate, materijalni izdaci i sl. (Gajdobranski i dr., 2017). $U$ vezi sa tim, opredeljenje proizvođača je putem slobodnog formiranja cena, čime se stvaraju uslovi za brži i stabilniji razvoj privrede, prate se bilansne potrebe zemalja za određenom vrstom poljoprivrednih proizvoda, što znači da proizvođači žele znati ko im je tzv. potencijalni kupac (Cvetković et al., 2014).

\section{DISKUSIJA / DISCUSSION}

Postavljen zadatak istraživanja zahtevao je primenu različitih metodoloških postupaka. Istraživanje se najvećim delom zasnivalo na tzv. „istraživanju za stolom" (desk research), i na prikupljanju raspoloživih primarnih i sekundarnih podataka. Istraživanje je obavljeno tokom vremenskog perioda od februara 2020. godine do februara 2021. godine, koji je obeležila pandemija COVID-19 (Gajdobranski et al., 2020).
$U$ radu su se koristile sledeće naučne metode: analitičko-sintetička, induktivno-deduktivna, metoda apstrakcije i konkretizacije, metoda generalizacije i specijalizacije, uz slikovit prikaz zadate teme.

$U$ radu se polazilo od hipteza (pretpostavki), koje su bile zasnovane na istraživanju sledećih segmenata:

- analizi poljoprivredne proizvodnje u izmenjenim uslovima i sa dovoljnom ponudom hrane za stanovništvo, uz korišćenje postojećih obradivih površina;

- izvozu agroindustrijskih proizvoda na svetska i tržišta evropske unije;

- snižavanju troškova poljoprivredno-prehrambenih proizvoda i povećanje kvaliteta, odnosno povećanje konkurentnosti;

- potrebama za unapređenje mera agrarne politike kroz podsticanje i subvencionisanje poljoprivredne proizvodnje;

- procenama o održivosti poljoprivredne proizvodnje uz korišćenje novih tehnologija i ljudskih resursa.

\section{ZAKLJUČAK / CONCLUSION}

Uvideli smo da obnovljivi izvori energije (biomasa i biogas), imaju dovoljan prirodni i tehnički potencijal, da bi se zadovoljili ukupni energetski zahtevi svetske populacije. Prirodni dnevni potencijal je čak 20 hiljada puta veći od dnevne potrošnje nuklearnih i fosilnih goriva, a među njima najveći izvor energije zauzima 
biomasa. Naša pažnja je usmerena na poljoprivrednu biomasu, čiji potencijal korišćenja kao izvora energije određuje dugoročnu održivost, koja uzima u obzir i efekte konkurentnosti kada je u pitanju proizvodnja hrane, zatim uticaj na biodiverzitet, kao i emisiju ugljen-dioksida prilikom sagorevanja. Rešenje za spas čovečanstva, nalazimo u obnovljivim izvorima energije koji se nalaze u prirodi, s tim da brzina njihovog trošenja ne premašuje brzinu nastajanja $u$ prirodi.

Veliki problem predstavlja održivost poljoprivredne proizvodnje, zbog sve većih nedostataka vode, koje prate česte i sve veće suše. Javnost je takođe izrazila zabrinutost da će se kulture i zemljišta namenjena proizvodnji hrane početi upotrebljavati za proizvodnju biogoriva, i to zbog upotrebe kultura kao što su kukuruz, pšenica, šećerna repa ili šećerna trska. Činjenica je da prema Evropskoj direktivi do 2025. godine treba smanjiti emisiju ugljen-dioksida za oko 20 odsto, povećati udeo obnovljivih izvora energije u ukupnoj potrošnji energije i povećati energetsku efikasnost za 20 odsto. Uz pridržavanje ovog paketa mera, poljoprivredna gazdinstva u novom proizvodnom sektoru mogu da proizvode biogas koji bi bio u skladu sa Evropskim standardima. Značaj se pridaje biofarmama gde se proizvodi biogas od tečnog i čvrstog stajnjaka, ostataka u poljoprivrednoj proizvodnji, kao i ostataka biomase nastalih preradom poljoprivrednih proizvoda.

U izmenjenim tržišnim uslovima, država je ostvarila punu kontrolu u izvozu poljoprivredno-prehrambenih proizvoda od strane registrovanih poljoprivrednih gazdinstava, $s$ tim da ako su potvrđene potrebne zalihe, dozvoljen je izvoz ulja, brašna, šećera i drugih osnovnih proizvoda. Pre i za vreme trajanja pandemije, cene osnovnih poljoprivredno-prehrambenih proizvoda (poput voća i povrća) su ostale stabilne, dok je nakon prekida vanrednog stanja došlo do veće ponude proizvoda i skoka cena (poput sezonskog voća). Stvaranje nove dodatne vrednosti poljoprivrednim gazdinstvima, može se ostvariti putem zaustavljanja spaljivanja biomase na njivama, kao i voćnjacima i vinogradima. Ovo bi predstavljalo jedan od osnovnih agroekoloških uslova u izmenjenim životnim okolnostima.

\section{LITERATURA / REFERENCES}

[1] Cvetković, S., Kaluđerović Radoičić, T., Vukadinović, B., Kijevčanin, M. (2014). Potentials and status of biogas as energy source in the Republic of Serbia. Renewable and Sustainable Energy Reviews, 31, 407-416.

[2] Gajdobranski, A. (2020). Uvod u zelenu ekonomiju (Udžbenik). Fakultet za informacione tehno- logije i inženjerstvo Univerziteta Union - Nikola Tesla, Beograd, str. 89.

[3] Gajdobranski, A. (2020). Obračunske kalkulacije u ratarskoj proizvodnji kod malih i srednjih gazdinstava na području AP Vojvodine (Monografija). Fakultet za poslovne studije i pravo i Fakultet za informacione tehnologije i inženjerstvo Univerziteta Union - Nikola Tesla, Beograd, str. 90.

[4] Gajdobranski, A., Krmpot, V., Janković, M. (2020). Uticaj klimatskih promena na eko-troškove proizvodnje zelenog goriva, Ecologica, Vol. 27, No 98, 260-265.

[5] Gajdobranski, A., Krmpot, V., Latković, D. (2020). Agriculture during the pandemic and expectations in the post period. University Union - Nikola Tesla, Belgrade, Faculty of information technology and engineering, Belgrade, Serbia, p. 104.

[6] Gajdobranski, A., Krmpot, V., Babić, V. (2017), Produktivnost $i$ troškovi kao važni društvenoekonomski apsekti privređivanja. 5th International Conference - Law, Economy and Management in Modern Ambience, LEMiMA 2017, Zbornik radova 1. Univerzitet Union - Nikola Tesla, Beograd (FPSP i FSOM), str. 321.

[7] Mentus, S., Jovanović, L. (2020). Napredne tehnologije u sprečavanju klimatskih promena, Ecologica, Vol. 27, No 100, 579-588.

[8] Nemački centar za istraživanje biomase (2016). Priručnik o biogasu: od proizvodnje do korišćenja (Interni materijal), Stručna agencija za obnovljive resurse, registrovano udruženje. OT Gülzow, str. 171.

[9] Prvi poslovni list poljoprivrednika i savetodavaca u Srbiji, Gazdinstvo, broj 155/Il, Agroprofit, Novi Sad, decembar 2020, str. 13.

[10] Subić, J., Kljajić, N., Jeločnik, M. (2017). Obnovljivi izvori energije i navodnjavanje u funkciji održivog razvoja poljoprivrede - ekonomski aspekti (Monografija). Institut za ekonomiku poljoprivrede, Beograd, str. 179.

[11] Todorović, M., Radosavljević, M., Gajdobranski, A. (2015). Ekonomski i ekološki aspekti korišćenja biomase. Naučna konferencija sa međunarodnim učešćem „MAK 2015“, Srbija na putu ka Evropskoj uniji, knjiga XVI, Etno centar - Gegula, Kopaonik, str. 9.

[12] http://powerlab.fsb.hr/neven/pdf/supervision_of_ msc_eq_thesis/Magistarski-rad-Igor-Raguzin.pdf. Datum posete stranici: 02.02.2021

[13] http://natalijadikovic.weebly.com/. Datum posete stranici: 02.02.2021

[14] http://www.zelenaenergija.pks.rs/ZelenaEnergija .aspx?id=3\&p=0\&. Datum posete stranici: 07.02. 2021. 
[15] https://www.eca.europa.eu/Lists/ECADocuments /SR16_18/SR_BIOFUELS_hr.pdf. Datum posete stranici: 07.02.2021

[16] https://educons.edu.rs/wp-content/uploads/2019 /12/Dejan-Supic-disertacija.pdf. Datum posete stranici: 12.02.2021
[17] https://www.agromedia.rs/vesti/u-srbiji-12postrojenja-za-preradu-biogasa/. Datum posete stranici: 12.02.2021

[18] http://www.esco.rs/biogas.html. Datum posete stranici: 13.02.2021. 